\title{
ONION GRADING PROTOTYPE BASED ON THE DIMENSIONS OF THE BULB USING PHOTORESISTOR
}

\author{
Aboamera, M. A. , Gamea, G. R. ${ }^{*}$ and Mohmed, M. E. **
}

\begin{abstract}
Grading of onion into size groups is often necessary in the food industry, to meet the requirements of some processing machines, or can be gradated as different grades according to the requirements of the market. The main objective of this study is to design, manufacture and evaluate the performance of grading prototype for onion based on the dimensions, which take place without physical contact. The prototype uses different successive operating components, such as photoresistor and actuators, each performing a specific task. Working principle of the grading prototype depend on the phototreistor, signal gathering circuit are also provided, a processing circuit and output circuit for distributing unit. When the onion bulb passes through the four sensors, it will shade the light signal sent by one or two or three or the four sensors according to bulb size, so the other sensors could not get the light signal, makes the sensors output voltage changes, the system receives digital signals produced by fruits that shadow the light from a photoresistor sensor during fruit measuring. After digital signals processed by the electronic circuit, every fruit's sizing level is deduced. Meanwhile, the control system will start to grade the bulb into a group according to bulb size, sending an executive order to the relative distributing motor to rotate for discharging this bulb to that group. Testing of the grading prototype was statistically factorial in completely randomized design, featuring three control factors (conveyor chain velocity, sphericity percentage of fruit and resting time) and three performance evaluation parameters (grading efficiency, damage percentage and productivity). The result showed that the best degree of grading efficiency obtained with the best degree of damage percentage were at $0.20 \mathrm{~m} / \mathrm{s}$ chain velocity and $1.5 \mathrm{sec}$ resting time.
\end{abstract}

\footnotetext{
* Associate prof. of Agric. Eng., Fac. of Agric., Minoufiya Univ. **Associate lecturer of Agric. Eng., Fac. of Agric., Minoufiya Univ.
} 
The best obtained values of grading efficiency were (85.25\%) with $(8.5 \%)$ damage fruit and $220 \mathrm{~kg} / \mathrm{h}$ productivity. The energy required was $130.1 \mathrm{Watt} / \mathrm{h}$. The cost of materials and manufacturing of the final grading prototype was 10000 L.E. The cost of grading prototype per hour was (4.912L.E).

\section{INTRODUCTION}

he term of grading can be applied to two distinct operations
which are: (1) sizing, in which the grades are segregated
according to their dimensions and(2) inspection, in which grades are based on the proportion of undesirable characteristics such as greening, cuts or other blemishes which are allowed to remain with the sound tubers and involves the elimination of unwanted material (Mcrae,1985). Sorting and grading are terms which frequently used interchangeably in the food processing industry. Sorting is a separation based on a single measurable property of raw material units, while grading is "the assessment of the overall quality of a food using a number of attributes".Grading of fresh product may also be defined as 'sorting according to quality', as sorting usually upgrades the product (Brennan, 2006). In recent ten years, operations in grading systems for fruits and vegetables became highly automated with mechatronics, and robotics technologies. Machine vision systems and near infrared inspection systems have been introduced to many grading facilities with mechanisms for inspecting all sides of fruits and vegetables (Kondo, 2009). Grading of fresh market fruits into size groups is convenient to assign market and price differentials of large and small produce, to match consumer preferences (most consumers prefer fruit classified into batches of uniform size), and probably most important, to allow pattern packing. The advantage of pattern packs over jumble packs is that they provide better protection of the produce (Peleg, 1985). Onion fruit can be classified manually, but this process is slow, high labor costs, worker fatigue, inconsistency, variability, and scarcity of trained labor and grading is done by visual inspection that could be error prone. As well as, the uniformity will be much better when sizing is done mechanically especially, when graded by electronic machine which consist of mechanical devices 
controlled electronically. This is a better method, since it produces a much more uniform classification.

Due to the lack of the small grading machinery to fit small farms, and higher prices of large grading machinery, therefore this study aimed to designing, manufacturing and evaluating the performance of a prototype for grading of onion which comprised a grading unit and a distributing unit based on the dimensions of the bulb using photoresistor.

\section{MATERIALS AND METHODS}

The materials and equipment which were used in this study can be summarized as follows:

\section{Grading prototype}

The designed prototype as presented in figures (1 and 2) consists of the following main parts:

1-Frame: It was constructed from steel angle $(40 \times 40 \mathrm{~mm})$ with $3 \mathrm{~mm}$ thickness and square shape iron steel $(40 \times 40 \mathrm{~mm})$ with $2 \mathrm{~mm}$ thickness welded together to connect all prototype unit.

2-Feeding unit: It consists of three parts, which are feeding hopper, conveyor chain and electrical direct current motor $(12 \mathrm{~V}, 4 \mathrm{~A})$.

3- Sensors unit: The main purpose of the sensors unit is to measures the vertical width or height of a bulb. The measure occurs during as it passes between two lateral vertical arrays of optical transducers based on the blocking of light. It is equipped with light emitting diodes (LEDs) and the other with photorisistor (figure -3).

4- Distributing motor unit: It consists, as sketched in figure (4), of the DC motor which can be rotate less than half revolution by gear box option and the frame which was constructed from equal-sided angle steel $40 \mathrm{~mm}$ side-length and $3 \mathrm{~mm}$ thickness. Funnel was constructed from galvanized smooth iron sheet and the dimensions of base were $100 \times 150 \mathrm{~mm}$. The dimensions of two side were $120 \times 150 \mathrm{~mm}$ all were welded together to make the funnel.

5- Electronic control unit: The control unit has been comprised a number of electronic circuits for controlling the feeding rates by 
means of the control in the feeding chain speed. The control system also measures the diameter of fruits individually by optical circuit which has been controlled in the position of the fruit outlet according to its category that has been determined by different optical circuit. The control unit consists of the following main systems of electronic circuits.

5-1:Power control system: The power system consists of transformers, Diode Bridge and full-wave rectification, AC to DC power supplies, voltage regulators and power supply distribution circuit.

5-2:Timing control system: The timing system, which has been used in the proposed grading prototype, is consisted of three timers. The first is used to control the time delay of light. The second used to control the lighting time and the third to control the stopping time of fruit in front of sensors unit. Figure (5) shows a timing diagram of operations and the sensors or motors either triggering events or causing motion using Timing Tool Editor 3.0.1 (2009) program.

5-3: Measuring control system: The main function of the measuring control system based on blocking light was to determine the dimension of the graded fruits as a volt value. The system has been consisted of photoresistor light sensor and light-emitting diode (LED) light source (figure (6). This circuit has been consisted of two IC LM339, two IC 7442, two IC 4069, one IC uln2003, four relays, four capacitor, four diode, eight photoresistor and eight variable resistor. The value of variable resistor depends on the input light intensity, ambient temperature, response speed, etc.

5-4: Distributing control system: Control system has been consisted of two parts the first angular position sensor (rotary potentiometer) that was installed below the shaft of distributing motor and the second control circuit to control in rotating of distributing motor and control in angles stand.

The grading prototype was used to grade onion (Giza variety). The bulb was obtained from the private farm in Minoufiya Governorate, Egypt. 


\section{METHODS}

The grading prototype was designed, manufactured and evaluated its performance in the workshop of Agricultural Engineering Department, Faculty of Agriculture, El-Minoufiya University. It is also characterized by a simple design most of its parts are locally available materials, low costs manufacture and ease of construction.

\section{Tested factors for onion grading}

1- Speed of conveyor chain, four-speed $(0.10,0.15,0.20,0.25 \mathrm{~m} / \mathrm{s})$.

2- Resting time of fruit, four periods $(1,1.5,2,2.5 \mathrm{sec})$ with measure signal delay time $(0.5,1,1.5,1.5 \mathrm{sec})$ respectively.

3- Spherisity $(<100 \%, 100 \%: 105 \%,>105 \%)$.

\section{Grading fruits}

\section{Physical characteristics of crops}

1. Determination of fruit dimensions

The mean dimensions of length (L), width (W), thickness (T) for each fruit estimated by digital venire caliper with accuracy of $0.01 \mathrm{~mm}$.

2. Volume

Volume of the individual onion bulb was measured by the liquid displacement method using toluene $\left(\mathrm{C}_{7} \mathrm{H}_{8}\right)$.

3. Determination of bulb densities

Bulb density was calculated for a random one hundred sample of fruits as follows:

$$
D_{r}=M / V_{l}, \mathrm{~g} / \mathrm{cm}^{3}
$$

Where:

$D r=$ Particle density of the individual fruit, $\mathrm{g} / \mathrm{cm}^{3}$;

$M=$ Mass of the individual fruit, $g$;

$V_{l}=$ Volume of the individual fruit, $\mathrm{cm} 3$. 

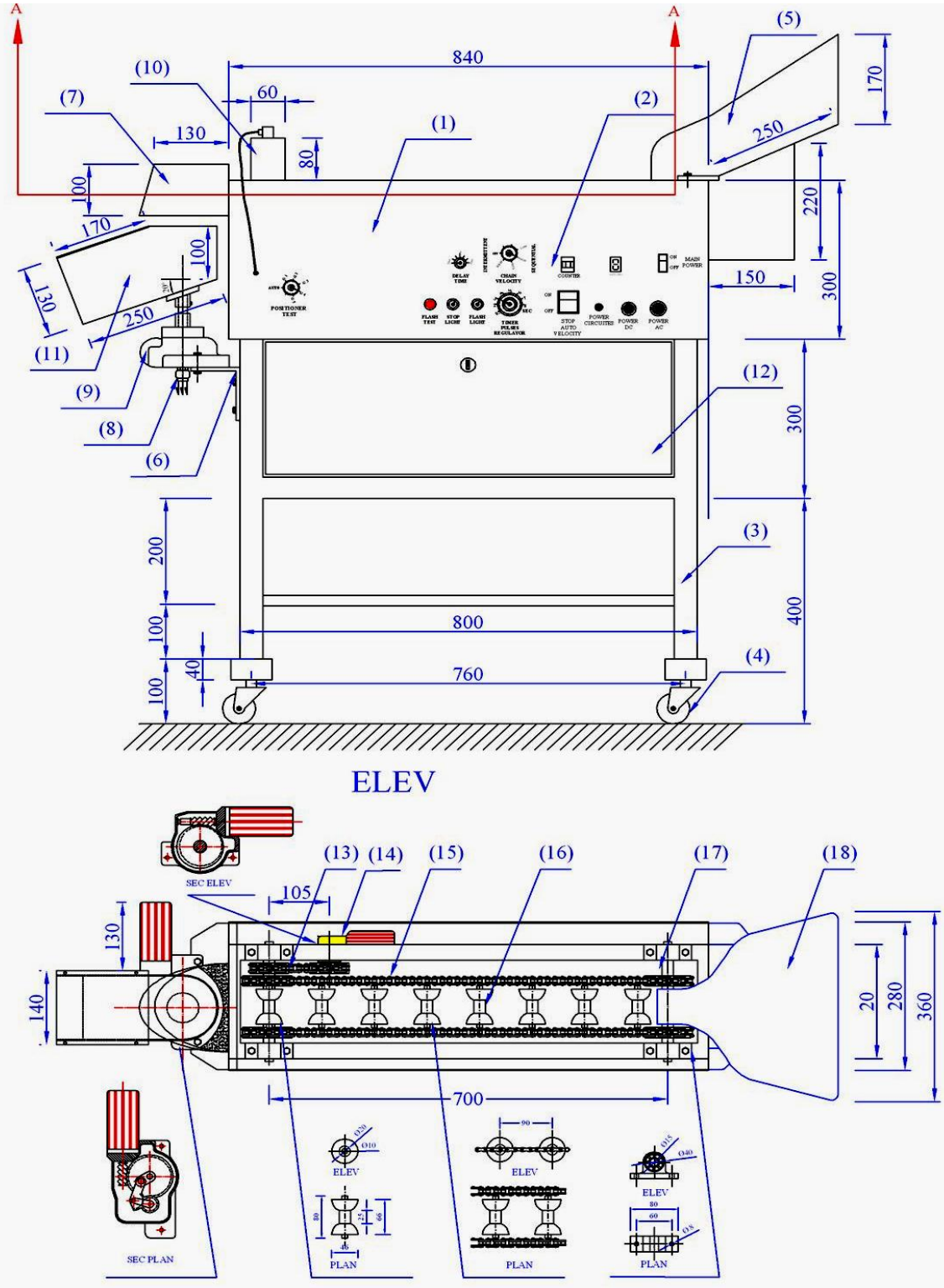

SEC PLAN AT A-A

1- Housing;

2- Control switch;

3- Frame;

4- Wheel;

5- Hopper holder;

6- Motor holder;
7- Cover;

8- Position sensor;

9- Electric DC motor of distributing;

10-Sensors unit;
11- Distributing Funnel;

12- Circuit box;

13- Chain;

14- Electric DC motor of conveyor chain;
15- Conveyor chain;

16- Rubber pulley;

17- Gear;

18- Feeding hopper.

DIMS. in mm

Fig. (1): Elev. and sectional plan of grading prototype (distributing motor). 

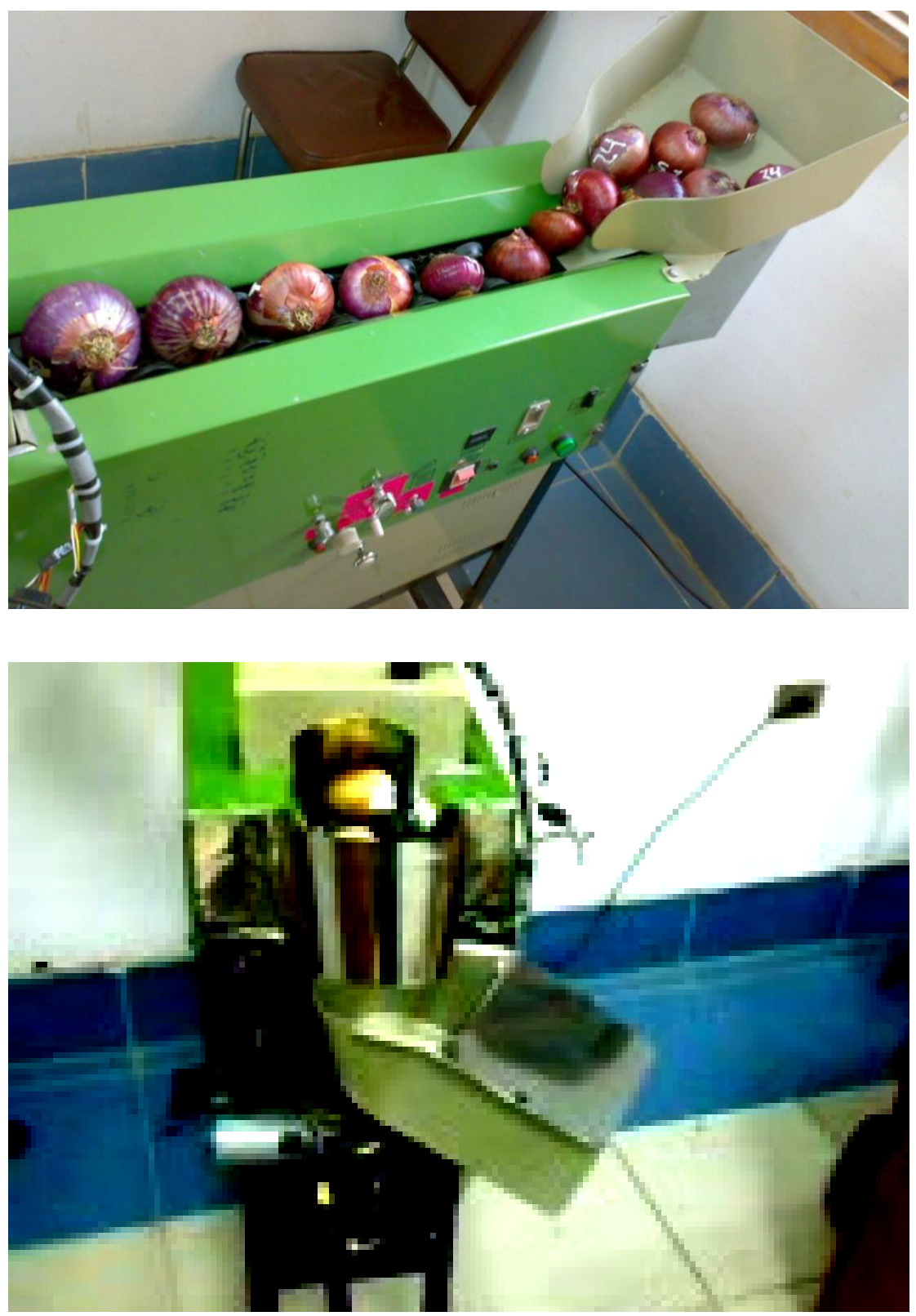

Fig. (2): Image of grading prototype (distributing motors). 


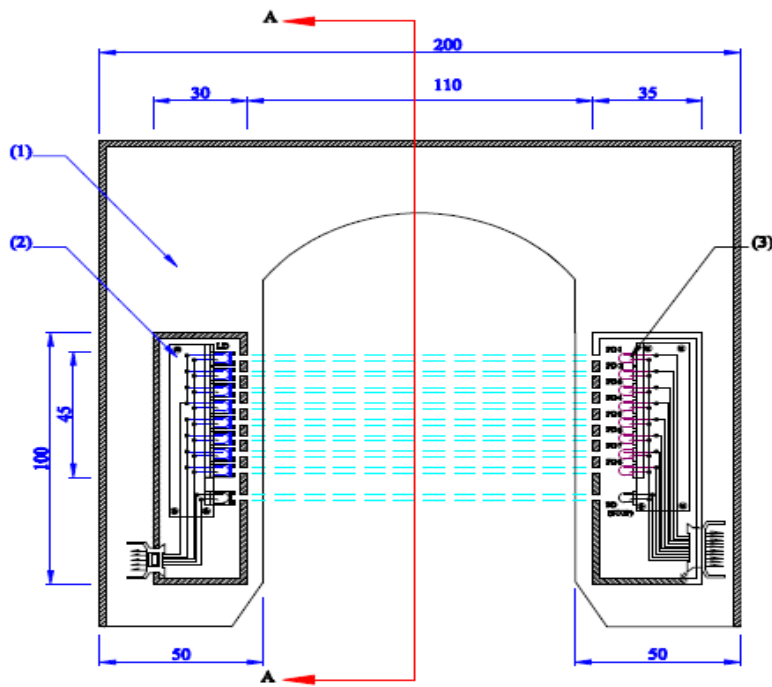

SEC ELEV AT B-B

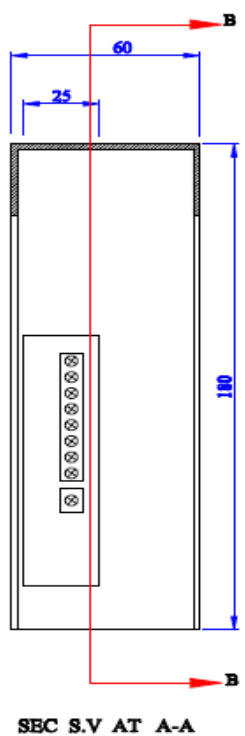

1-Housing, 2-Array of light emitting diode, 3-Array of optical sensor

Fig. (3): Schematic diagram of sensors unit

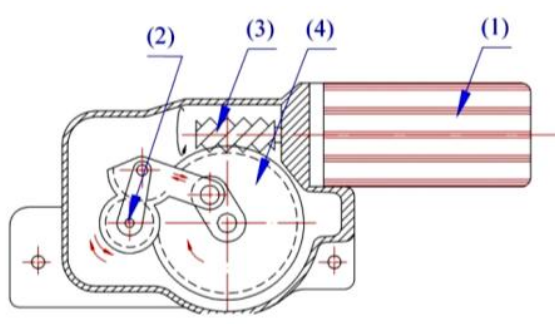

Sectional plan

\section{1- DC motor}

2- Distributor gear;

3; and 4-Worm gear.

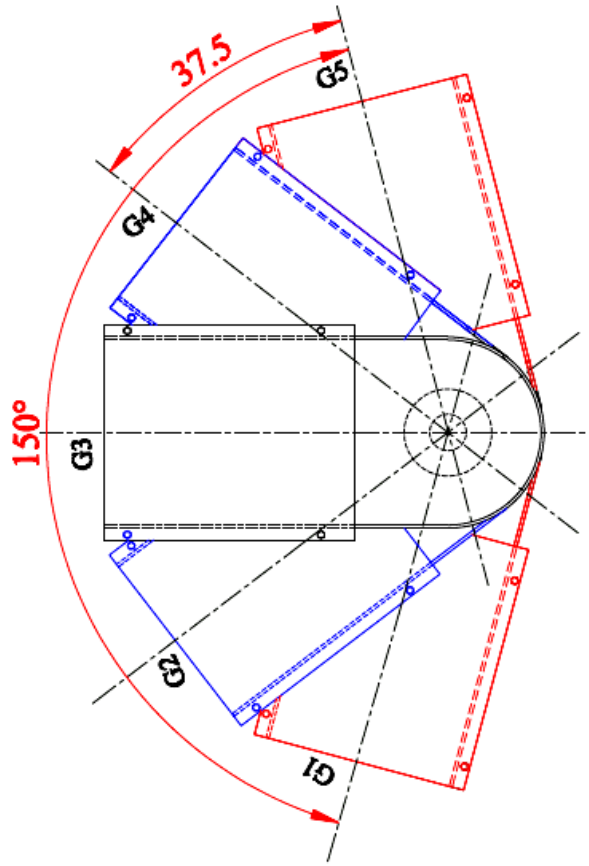

Fig. (4): Schematic diagram of distributing motor and position angle 


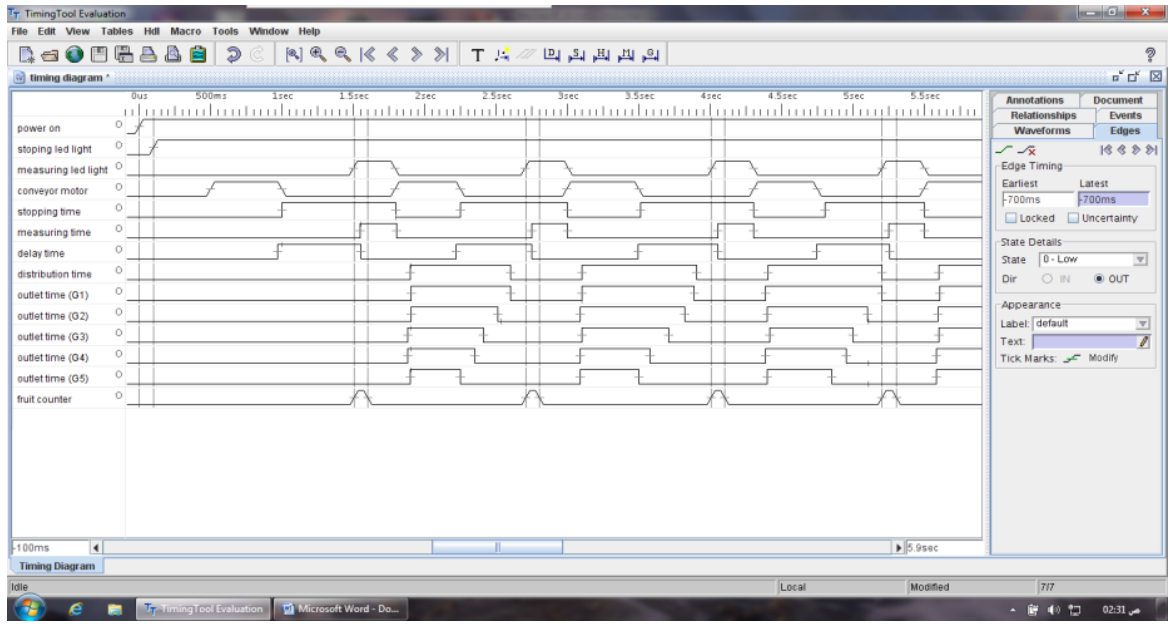

Fig(5) Interface of (Timing Tool Editor 3.0.1 (2009)) program

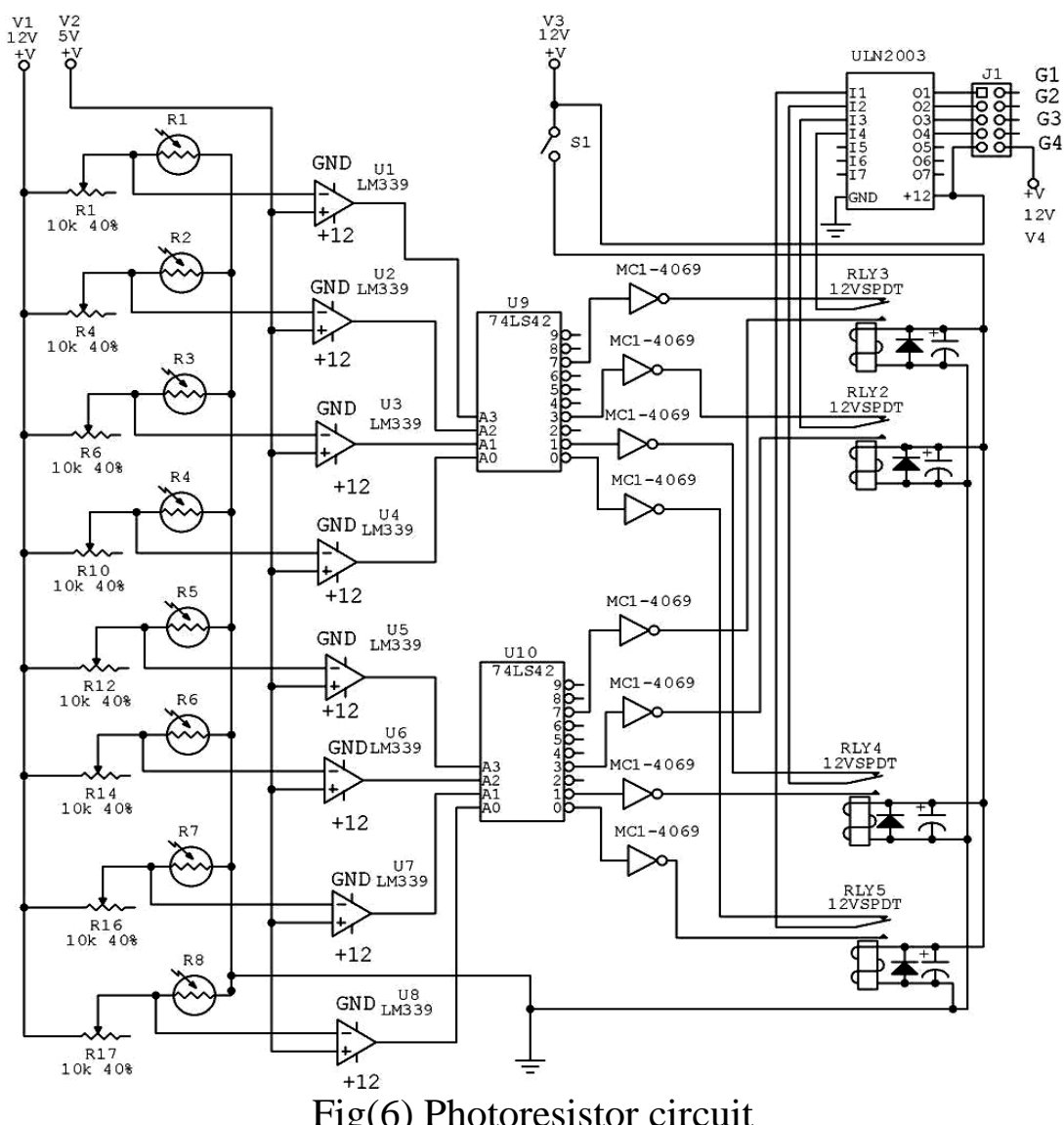


4. Determination of static and dynamic coefficient of friction The static friction angle for fruits was measured against two structural materials, rubber and galvanized iron. The board, on which the material was fixed, was tilted slowly and gradually until the bulbs overcomes the static friction and begins to slide downwards over the plane. On the other hand, the dynamic coefficient of friction device as showed in Fig (7) was designed and fabricated. It was used to measure the dynamic coefficient of friction for onion on two different surfaces disk of $40 \mathrm{~mm}$ diameter.

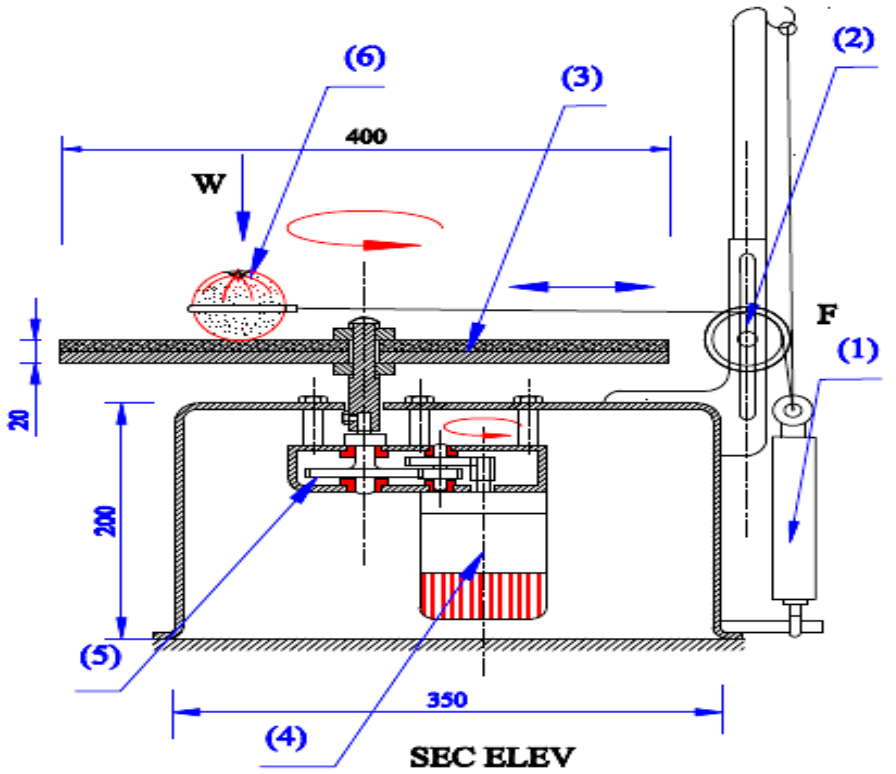

1. Digital balance,

3.Rotating disk,

2. Roller,

4. Motor,

5. Gear box

6. Fruit

Fig. (7): Schematic diagram of coefficient of static friction apparatus.

\section{Sphericity}

According to the most commonly used definition, sphericity is the ratio of volume of solid to the volume of a sphere that has a diameter equal to the major diameter of the object so that it can circumscribe the solid sample. For a spherical particle of diameter $D p$, sphericity is equal to (mohsenin, 1970).

Sphericity $=\frac{\text { geometric mean diameter }}{\text { major diameter }}=\frac{(a b c)^{\frac{1}{3}}}{a}$. 
PROCESS ENGINEERING

\section{where:}

\section{Projected area}

$$
\begin{aligned}
& a=\text { longest intercept } \\
& b=\text { longest intercept normal to } a, \\
& c=\text { longest intercept normal to } a \text { and } b .
\end{aligned}
$$

Projected area of onion obtained from a proposed device is based on image processing. Captured images from a camera were transmitted to a computer card which works as an analog to digital converter. Digital images were then processed to the software and the desired parameters were determined.

\section{Evaluation parameter of grading machine}

\section{Grading efficiency}

The total grading efficiency of the prototype was estimated according to (Klenin et al., 1985) and (Ismail, 1995 in Arabic reference) and using the following formula:

$$
\eta_{G}=\left(w_{1}+w_{2}+w_{3}+w_{4}+w_{5}\right) / w \%
$$

Where:

$\eta_{G}=$ total prototype grading efficiency $(\%)$,

$w=$ total weight of fruit in $\mathrm{kg}$,

$w_{1}, w_{2}, w_{3}, w_{4}$ and $w_{5}=$ weight of fruit in different collected grading fruit from collected box $A, B, C, D$ and $E,(\mathrm{~kg})$.

\section{Damage percentage}

Damage percentage calculated according to the formula as follow:

$$
D_{p}=\frac{W_{1}-W_{2}}{W_{1}}
$$

Where:

$$
\begin{aligned}
& D_{p}=\text { damage percentage }(\%) ; \\
& W_{1}=\text { total mass weight of fruit before grading }(\mathrm{kg}) ; \\
& W_{2}=\text { total weight of un damage fruit after grading }(\mathrm{kg}) .
\end{aligned}
$$

\section{Electric power}

A digital clamp meter and Voltmeter were used for measuring current intensity and voltage respectively. The electric power $(\mathrm{P}$, Watt) was calculated based on current intensity (I, Ampere) and the voltage $(\mathrm{V}$, volt) measurements, using the following formula:

$$
P=\operatorname{Cos} \emptyset . I . V \text {. }
$$


PROCESS ENGINEERING

Where:

Cos $\emptyset$ Power factor (being equal to 0.85)

4. Prototype productivity

The prototype has a theoretical capacity, which varies with the grading time period per hour and the weight of fruit per period. If there are known, the productivity of the prototype may be determined by using the following equation:

Prototype productivity, $(\mathrm{kg} . / \mathrm{h})=W \times P_{n}$

Where:

$$
\begin{aligned}
& W=\text { The weight of fruit per period, } \mathrm{kg} \\
& P_{n}=\text { Grading period time per hour. }
\end{aligned}
$$

\section{Cost analysis:}

The operation cost of grading prototype was calculated according to the formula based on the initial cost of prototype, interest on capital, cost of the power requirements $\left(\mathrm{P}_{\mathrm{c}}\right)$, cost of maintenance, and wage of operator according to the following (Awady, 1978):

$$
\begin{aligned}
& C=P / h(1 / e+i / 2+t+r)+\left(P_{c} \times S\right)+W / 144 \ldots \ldots \ldots \\
& \text { Where: } \\
& C \quad=\text { Hourly cost }(\text { L.E } / \mathrm{h}), \\
& P \quad=\text { Price of prototype }(10000 \mathrm{L.E}), \\
& h \quad=\text { Yearly operating hours }(1344 \mathrm{~h}), \\
& e \quad=\text { Life expectation }(10 \text { year }), \\
& i \quad=\text { Interest rate }(10 \%), \\
& t \quad=\text { Overheads ratio }(3 \%), \\
& r \quad=\text { Repairs ratio of the total investment }(1 \%), \\
& P_{c} \quad=\text { power requirements }(0.16 \mathrm{~kW}), \\
& S \quad=\text { Price of power requirements per }(0.2 \mathrm{~kW} / \mathrm{h}), \\
& W \quad=\text { Labour wage rate per month in }(500 \mathrm{L.E}), \\
& 144 \quad=\text { Reasonable estimation of monthly working hours. }
\end{aligned}
$$

\section{RESULTS AND DISCUSSIONS}

Results obtained can be reported as follows:

\section{Physical characteristics of onion}

Physical characteristics of onion (Giza red), can be summarized as follows:

Length $(59.79 \pm 7.82 \mathrm{~mm})$ Width $(69.21 \pm 8.6 \mathrm{~mm})$, density $(0.87 \pm 0.03$ $\left.\mathrm{g} / \mathrm{cm}^{3}\right)$, volume $\left(143.03 \pm 58.17 \mathrm{~cm}^{3}\right)$, weight $(122.42 .472 \pm 46 \mathrm{~g})$, sphericity percentage $(110.49 \pm 6.41 \%)$, the minimum height caused 
damage $(100 \pm 20.41 \mathrm{~cm})$, coefficient of dynamic friction of the fruits on galvanized iron sheet $(0.46 \pm 0.01)$ and on rubber $(0.71 \pm 0.04)$ and the static coefficient of friction on galvanized iron sheet $(0.48 \pm 0.01)$ and on rubber $(0.72 \pm 0.01)$ and the rolling angle $(13.57 \pm 0.24)$.

\section{Performance evaluation of grading prototype}

1.Grading efficiency

Fig (8) shows the effect of conveyor chain velocity on grading efficiency for onion at different values of stopping time (1, 1.5, 2 and $2.5 \mathrm{sec})$ and different percentage of sphericity $(<100 \%$, Between 100 to $105 \%$ and $>105 \%)$. The result showed that, grading efficiency decreased with increasing conveyor chain velocity, decreasing the stopping time and decreasing the sphericity percentage. The effects of the interaction between conveyor chain velocities and stopping time on grading efficiency were highly significant. The highest grading efficiency was $92.28 \%$ at $0.1 \mathrm{~m} / \mathrm{s}$ conveyor chain velocity, $2.5 \mathrm{sec}$ stopping time and sphericity percentage less than $100 \%$. While the lowest grading efficiency was $78.96 \%$ at $0.25 \mathrm{~m} / \mathrm{s}$ conveyor chain velocity, $1 \mathrm{sec}$ stopping time and sphericity percentage more than $105 \%$.This would lead to lower measurement accuracy due to non-uniformity of movement and the cause no stand the fruit in specific measure spaces due to the fruit acquisition of large kinetic energy.The interactions between four different conveyor chain velocities and stopping time values and sphericity percentage levels were highly significant.

\section{Percentage of damage}

Fig (9) indicated the effect of conveyor chain velocity on the mean value of the damage percentage at different values of stopping time and sphericity percentage for onion. The highest damage percentage for onion $(14.7 \%)$ was observed at the interaction of $0.25 \mathrm{~m} / \mathrm{s}$ conveyor chain velocity and sphericity percentage more than $105 \%$ and $1 \mathrm{sec}$ stopping time. While, the lowest damage percentage $(3.2 \%)$ was observed at the interaction of $0.1 \mathrm{~m} / \mathrm{s}$ conveyor chain velocity and sphericity percentage less than $100 \%$ and $2.5 \mathrm{~s}$ stopping time.

\section{Consumptive energy}

The power required decreased when the stopping time increases from 1 to 2.5 sec for all conveyor chain velocity. Also, increasing the conveyor chain velocity increased the energy required. The average value at $0.20 \mathrm{~m} / \mathrm{s}$ conveyor chain velocity, $1.5 \mathrm{sec}$ stopping time and $1 \mathrm{sec}$ measurement delay time was 130.1 Watt / $\mathrm{h}$ for onion .as shown in fig.(10) 

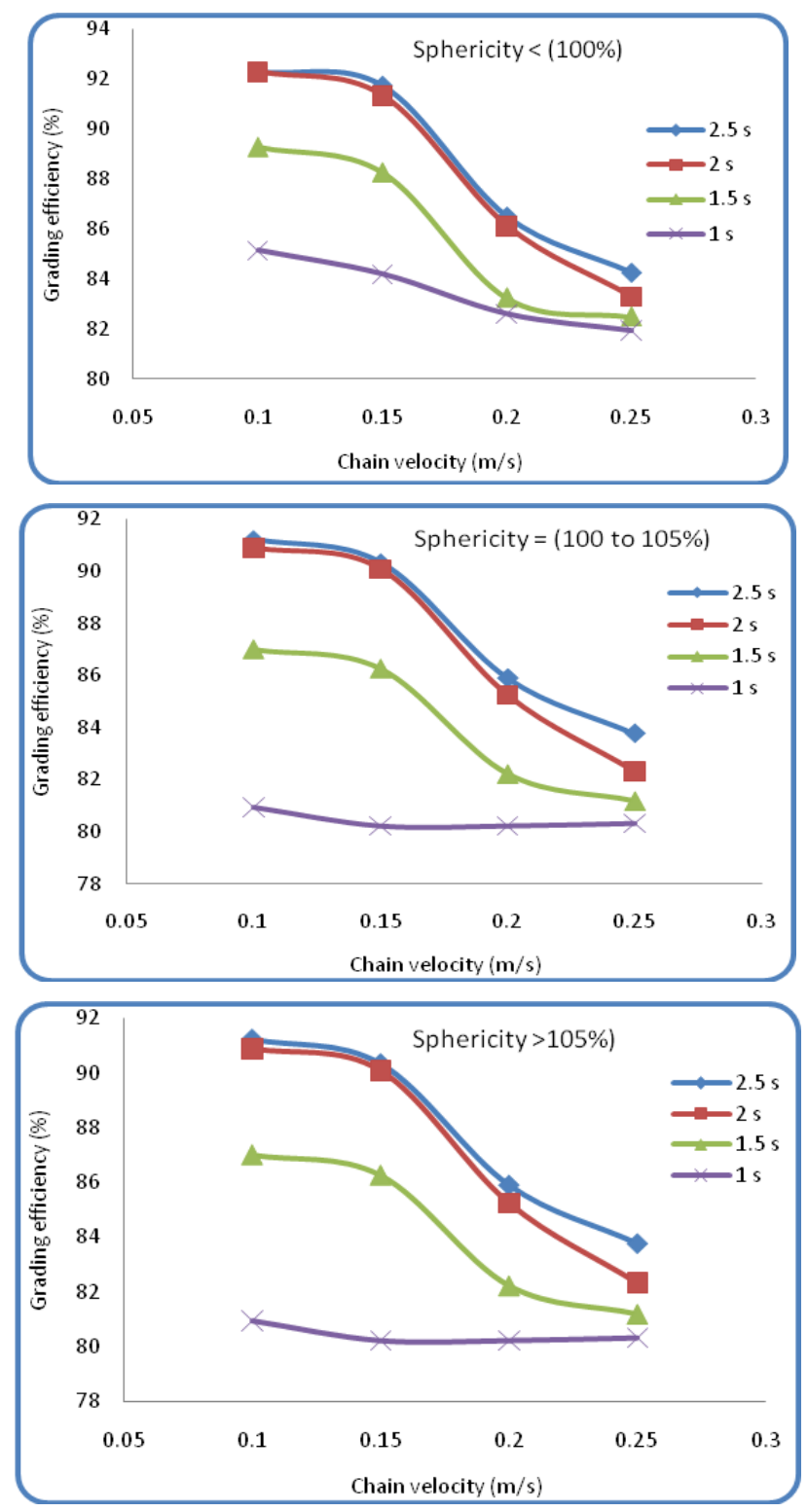

Fig. (8): Effect of conveyor chain velocity on the grading efficiency at different values of stopping time and sphericity percentage for onion.

\section{$\underline{\text { 4. Productivity of grading prototype }}$}

From figure (11) it shown that, increasing the chain velocity from 0.1 to $0.25 \mathrm{~m} / \mathrm{s}$ tended to increase the total productivity of the grading prototype for all the stopping time periods and all different kind of 
crop. Increasing stopping time from 1 to $2.5 \mathrm{sec}$ tended to decrease the total productivity of the grading prototype. The highest productivity of grading prototype for onion $(325 \mathrm{~kg} / \mathrm{h})$ was observed at the interaction of $0.25 \mathrm{~m} / \mathrm{s}$ conveyor chain velocity and $1 \mathrm{sec}$ stopping time. While, the lowest productivity of grading prototype $(130 \mathrm{~kg} / \mathrm{h})$ was observed at the interaction of $0.1 \mathrm{~m} / \mathrm{s}$ conveyor chain velocity $2.5 \mathrm{sec}$ stopping time.

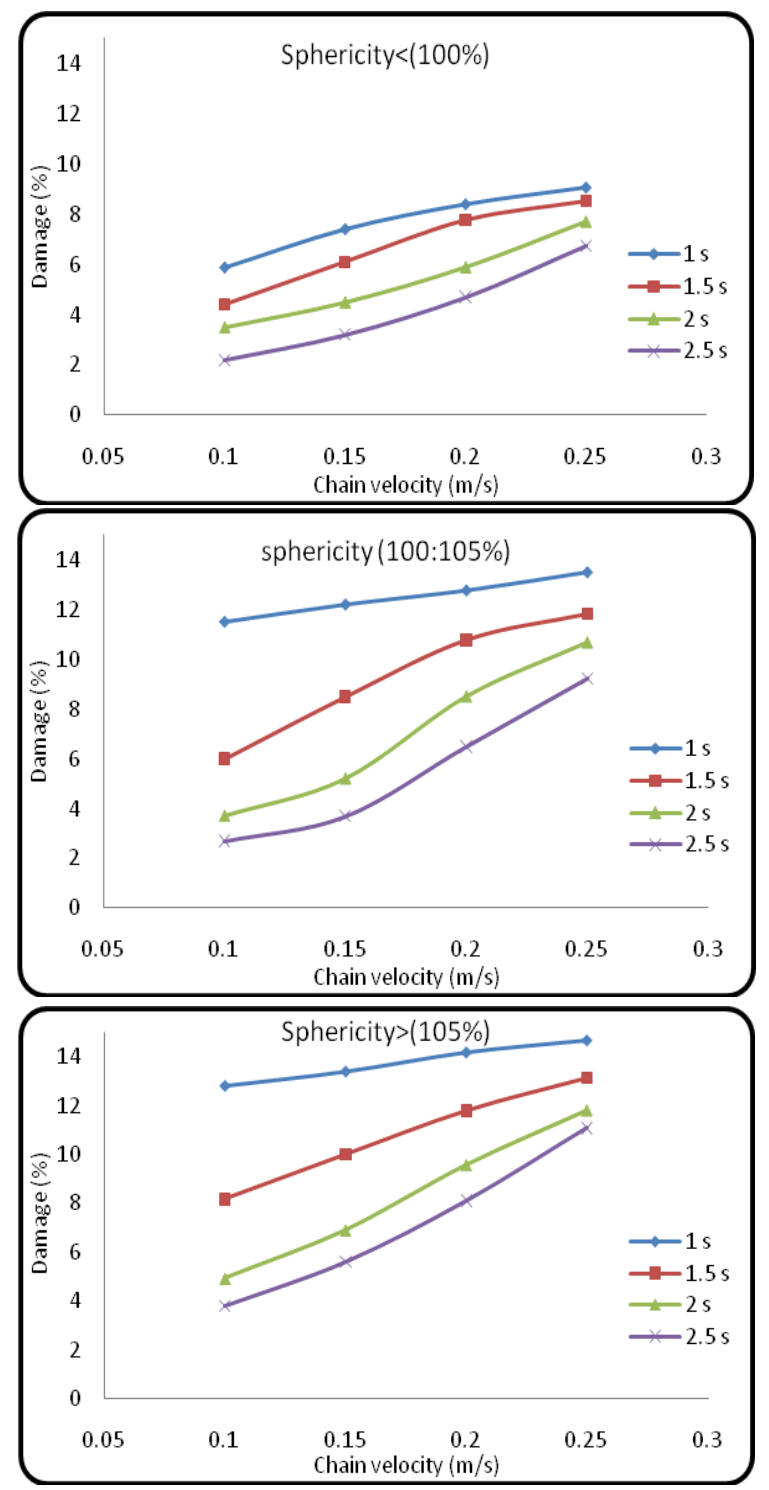

Fig. (9): Effect of chain velocity on damage percentage efficiency at different value of stopping time and sphericity percentage for onion. 


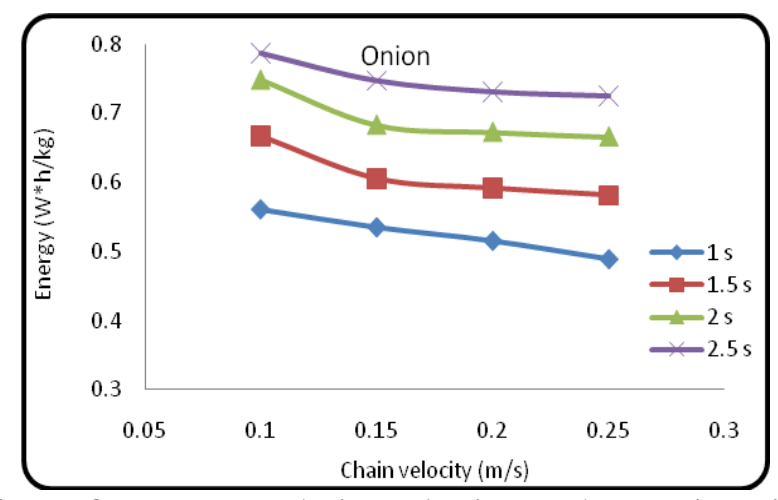

Fig.(10): Effect of conveyor chain velocity and stopping time on energy required for grading prototype .

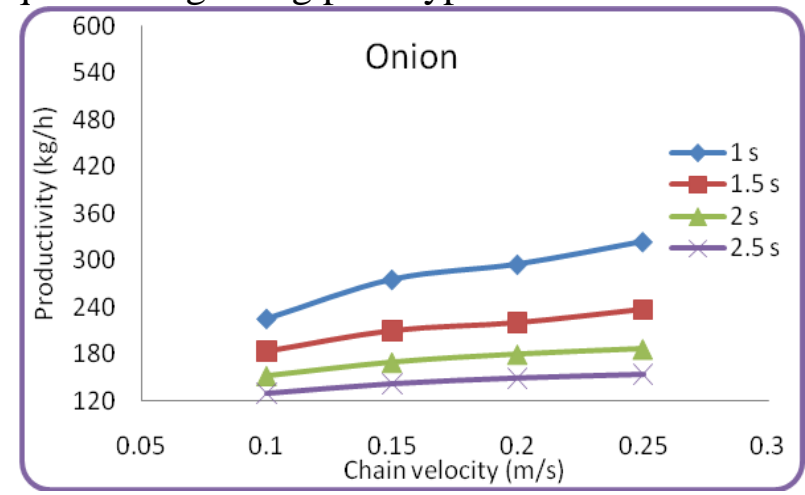

Fig.(11): Effect of conveyor chain velocity and stopping time on productivity of grading prototype.

\section{Economic evaluation}

The cost evaluation of the prototype was performed at the best results of damage percentage, best efficiency and higher productivity at grading operations for onion. As the best velocity of the conveyor chain was 0.20 $\mathrm{m} / \mathrm{s}$ and a period of $1.5 \mathrm{sec}$ stopping time. The cost of materials and manufacturing of the final grading prototype was 10000 L.E. The cost of grading prototype per hour was (4.918 L.E/h).

\section{CONCLUSION}

Increasing the conveyor chain velocity from 0.10 to $0.25 \mathrm{~m} / \mathrm{s}$ led to increased the productivity but it led to decreased the prototype efficiency and increased the percentage of damage at all different factors. The grading efficiency increased with increasing the stopping and delay of measurement time. As well as increasing the stopping time lead to 
decreased the percentage of damage, but also decreased the prototype productivity. The best degrees of grading efficiency obtained with the best degrees of damage percentage were at $0.20 \mathrm{~m} / \mathrm{s}$ chain velocity and $1.5 \mathrm{sec}$ Stopping time. The highest obtained values of grading efficiency were $(85.25 \%)$ with $(8.5 \%)$ damage fruit. the energy required was 130.1 Watt $/ \mathrm{h}$. The cost of materials and manufacturing of the final grading prototype was 10000 L.E. The cost of grading prototype per hour was (4.912 L.E). This prototype of grading succeeded for purpose as a step forward to the complete design for optimal grading machine.

\section{REFERANCES}

Brennan J. G., Butters, J. R., Cowell, N.D, Lilly, A.E.V. (1990), Food Engineering Operations, 3rd edn, Elsevier Applied Science, London.

Kondo, N. (2009), Automation on fruit and vegetable grading system and food traceability", Trends in Food Science \& Technology, doi: 10.1016/j.tifs.

Mohsenin, N.N. (1970), Physical Properties of Plant and Animal Materials. New York: Gordon and Breach.

Mcrae, D. C. (1985), A Review of Developments in Potato Handling and Grading. J. agric. Engng Res. 31,115-1 38.

Klenin, N. I.; I. F. Popov and V. A. Sakun, (1985), Agricultural Machines (Theory of operation, computation of controlling parameters and the conditions of operation). Amerind publishing co. PVT. LTD. New York.

Mcgechan, M. B. (1980), An investigation into the damage sustained by different varieties of potatoes during ridding to removal soil. J. Agric. Eng. Res. V. n. 4, 345-353.

Awady, M. N. (1978), Engineering of tractors and agricultural machinery, Text book., col. Of Agric., Ain Shams Univ., $5^{\text {th }}$ Ed.: 164-167.

Peleg, K., (1985), Chapter 5: sorting operations. In: Produce Handling, Packaging and Distribution. AVI Publishing Co., Westport, Conn., pp. 53-87.

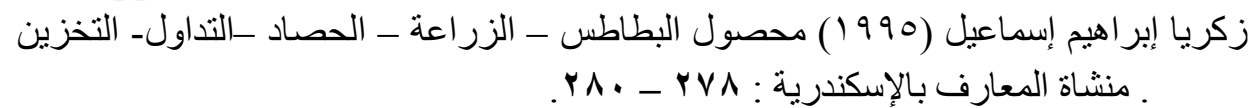




\section{الملخص العربي \\ نموذج مبئي لتدريج البصل يعتمد علي أبعاد البصلة \\ باستخدام المقاومات الضولئية}

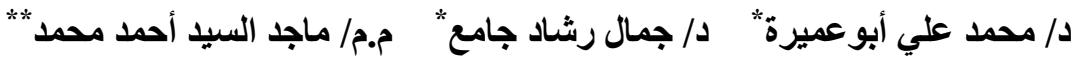

تعتبر عملية التدريج للبصل من أهم عمليات الإعداد الجيد لتحديد قيمته التجارية و يضمن تناسقا

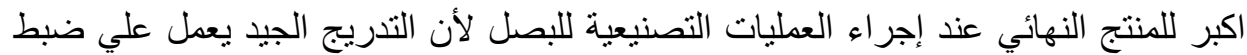

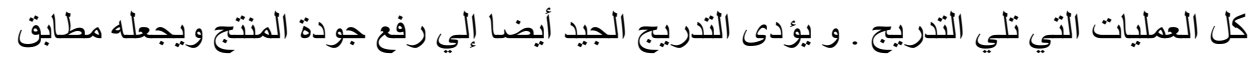
للمو اصفات المحددة لكل درجة حسب متطلبات السوق المحلية و العالمية في حالة التصدير ـ كذلك فان التدريج غير المتقن قد يقلل من جودة المنتج وقبول المستهلك. ويلاحظ أن التدريج اليدوي لله

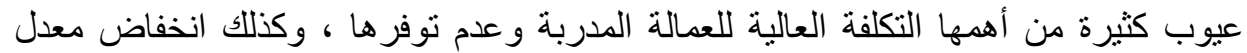

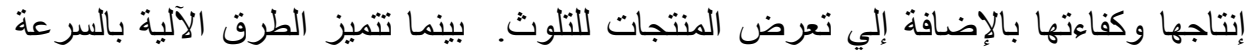

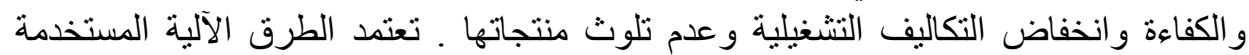

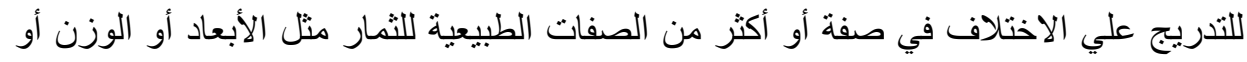

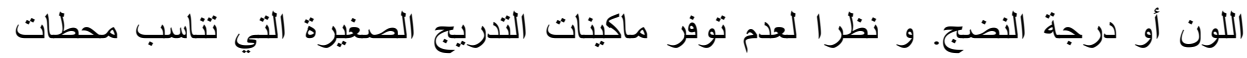

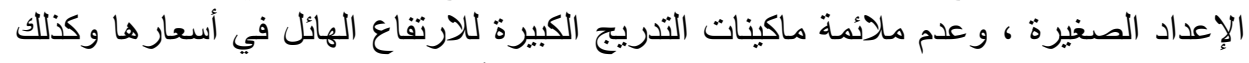

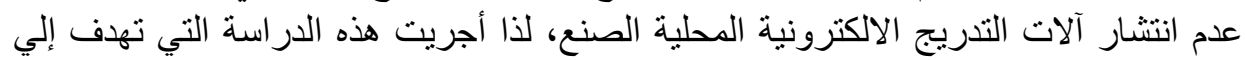

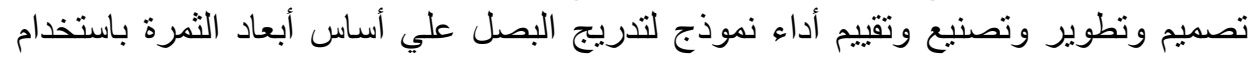

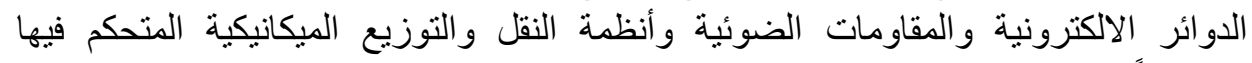

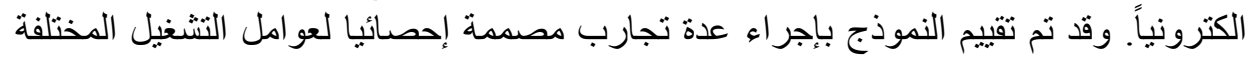

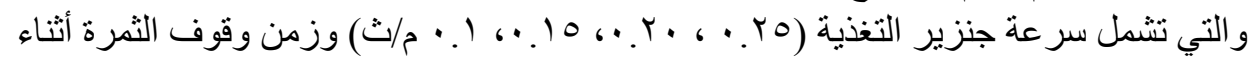

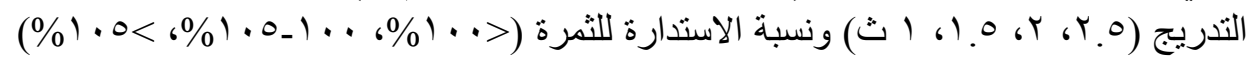

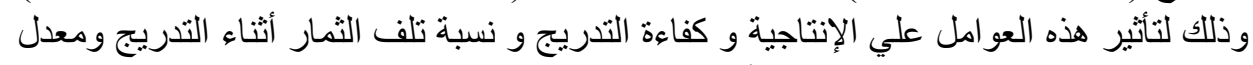

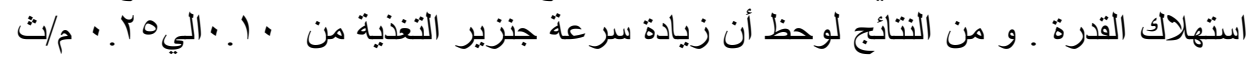

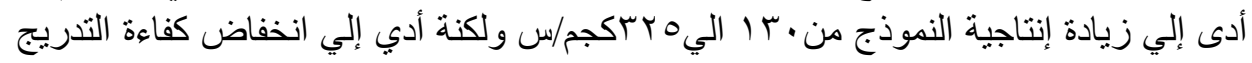

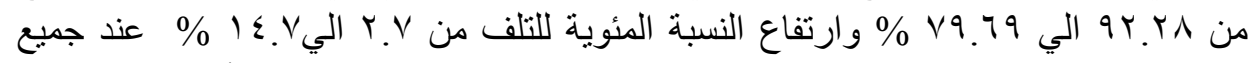

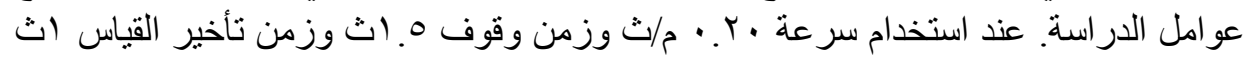

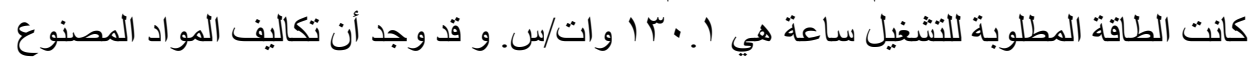

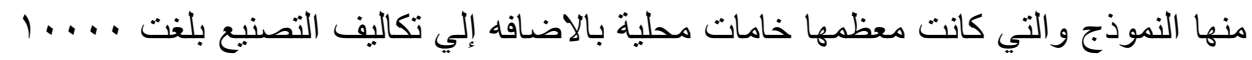

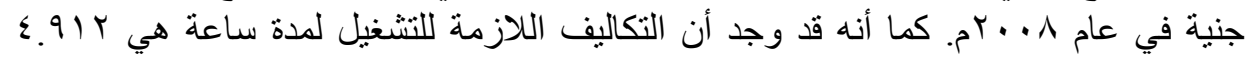

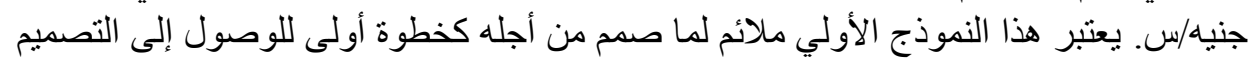

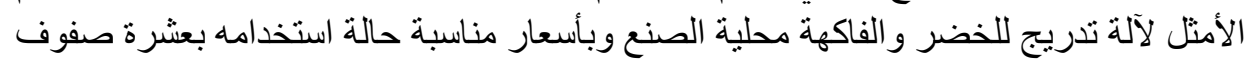

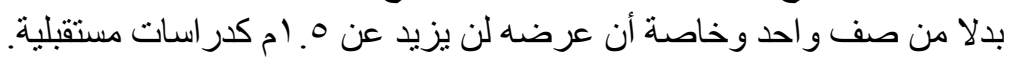

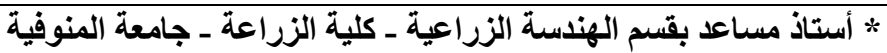

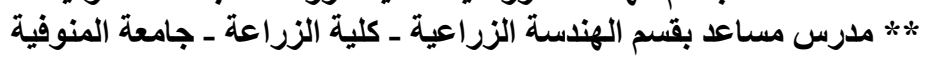

